University of Nebraska - Lincoln

DigitalCommons@University of Nebraska - Lincoln

$6-2020$

Representaciones textiles en los iconos de la litoescultura

Tiwanaku: distribución y significado / Textile representations in the iconography of the Tiwanaku lithic sculpture: distribution and meaning

Carolina Aguero

Arturo Martínez

Follow this and additional works at: https://digitalcommons.unl.edu/pctviii

Part of the Art and Materials Conservation Commons, Fiber, Textile, and Weaving Arts Commons, Indigenous Studies Commons, Latin American Languages and Societies Commons, Museum Studies Commons, and the Other History of Art, Architecture, and Archaeology Commons

This Article is brought to you for free and open access by the Centre for Textile Research at DigitalCommons@University of Nebraska - Lincoln. It has been accepted for inclusion in PreColumbian Textile Conference VIII / Jornadas de Textiles PreColombinos VIII (2019) by an authorized administrator of DigitalCommons@University of Nebraska - Lincoln. 


\title{
Representaciones textiles en los iconos de la litoescultura Tiwanaku: distribución y significado
}

\section{Textile representations in the iconography of the Tiwanaku lithic sculpture: distribution and meaning}

\author{
Carolina Agüero ${ }^{1}$ \& Arturo Martínez ${ }^{2}$
}

\begin{abstract}
Resumen
Se presenta la síntesis de una investigación destinada a identificar representaciones textiles en los iconos de la litoescultura Tiwanaku. Previamente ya habíamos usado un análisis componencial para segregar motivos y elementos en sus tres principales figuras: Personaje Frontal, Personajes de Perfil y Banda Faja. Luego se ubicaron sus referentes textiles en colecciones arqueológicas de Chile, Perú y Bolivia para precisar patrones de distribución espacial de las prendas y su iconografía en las distintas zonas que estuvieron en la órbita de Tiwanaku. Además, este estudio ha sido complementado con una exploración de los saberes ancestrales acerca de los iconos que están plasmados en estas figuras y que dicen relación con "plantas medicina o plantas maestras”. Esto, junto a lo que su distribución diferencial puede estar indicando, abren nuevas e interesantes aproximaciones interpretativas.
\end{abstract}

Palabras claves: Tiwanaku, escultura lítica, representaciones textiles, plantas maestras, arqueología colaborativa.

\begin{abstract}
We present a synthesis of an investigation designed to identify textile representations in the icons of the Tiwanaku lithic sculpture, using a componential analysis to segregate motifs and elements in its three main figures: Frontal Personage, Profile Personage and Belt Band. Then the textiles depicted are identified in archaeological collections in Chile, Peru and Bolivia in order to define patterns of spatial distribution of the garment types and their iconography in different areas of the Tiwanaku sphere. In addition, this study has been complemented with an exploration of ancestral knowledge about the icons embodied in these figures that relates to medicine plants or master plants. Together with what the differential distributions may indicate, this opens up new and interesting interpretative approaches.
\end{abstract}

Keywords: Tiwanaku, lithic sculpture, textile representations, master plants, collaborative archaeology.

\begin{abstract}
Résumé
Nous présentons la synthèse d'une recherche destinée à identifier les représentations textiles dans les icônes de la sculpture lithique Tiwanaku en utilisant une analyse componentielle afin de distinguer les motifs et les éléments présents dans ses trois principales figures : Personnage Frontal, de Profil et Ceinture. Ensuite les textiles référencés ont été identifiés dans les collections archéologiques du Chili, du Pérou et de Bolivie pour définir les modèles de distribution spatiale des tissus et leur iconographie dans les différentes zones d'influence de Tiwanaku. Aussi, cette étude a été complétée par l'exploration

1. Arqueóloga. Instituto de Investigaciones Arqueológicas y Museo, Universidad Católica del Norte, San Pedro de Atacama, CHILE. CP 14100oo. Email: maguero@ucn.cl

2. Hombre Medicina.
\end{abstract}

DOI: 10.32873/unl.dc.zea.1204

Published in PreColumbian Textile Conference VIII / Jornadas de Textiles PreColombinos VIII, ed. Lena Bjerregaard and Ann Peters (Lincoln, NE: Zea Books, 2020). https://digitalcommons.unl.edu/zeabook/ 
des savoirs ancestraux sur les icônes reproduites dans ces figures et qui sont liées à la consommation de substances psychoactives. Ces éléments, ajoutés à ce que semble indiquer la répartition différentielle, ouvre de nouvelles et intéressantes approches interprétatives.

Mots-clés: Tiwanaku, sculpture lithique, représentations textiles, substances psychoactives, archéologie collaborative

\section{Introducción}

Varios autores habían notado relaciones formales entre la iconografía de la litoescultura Tiwanaku y los textiles (p.e. Conklin 1983; Cordy-Collins 1976). Las esculturas y sus figuras grabadas aparecen usando cintillos, tocados, túnicas y bolsas. Bennett (1946) consideró que los diseños textiles probablemente influenciaron la totalidad del estilo Tiwanaku al identificar patrones textiles en las esculturas del sitio-tipo, particularmente en el monolito que lleva su nombre. También Conklin (1983) sugirió que algunas bandas cefálicas encontradas en momias de Pisagua son las mismas representadas en las cabezas de los monolitos de Tiwanaku, y vió en un friso depositado en el Museum für Volkerkunde (actualmente Ethnologisches Museum), en Berlín, trazas de pintura que insinúan que la arquitectura Tiwanaku estaba pintada con colores similares a los usados en los textiles. Asimisno, Oakland (1986) y Berenguer y Dauelsberg (1989) observaron estrechas similitudes entre las túnicas de los Personajes Frontales y aquellas encontradas en los cementerios del norte de Chile, así como en los gorros de cintillo y casquete de algunos monolitos y aquellos de San Pedro de Atacama (Berenguer 1993). También Zighelboim (1991 Ms.) ha sostenido que la Puerta del Sol es en sí, la representación de un textil: una túnica con su faja. En suma, abundan las sugerencias respecto a que las esculturas Tiwanaku fueron pensadas como representaciones textiles (p.e. Puerta del Sol y Puerta de la Luna) y también como representaciones de personajes que usan prendas textiles (p.e. monolitos Bennett y Ponce).

En esta oportunidad hemos retomado un trabajo realizado hace varios años (Agüero 2001 Ms.; Agüero et al. 2003) proponiéndonos como objetivos principales identificar representaciones de textiles en los iconos de la litoescultura Tiwanaku, ubicar sus referentes en las colecciones arqueológicas, precisar sus patrones de distribución espacial, y con la actual ayuda y conocimientos de Arturo Martínez, aventurarnos en lo que esto probablemente signifique (Figura 1).

El análisis consideró los siguientes soportes líticos: Puerta del Sol, Puerta de la Luna, Monolito Bennett, Monolito Ponce, Monolito El Fraile, Estatuilla de Puno, Kochamama, Idolo del Sol, Bloque de Llojeta, Lito de Takiri, Receptáculo Lítico de Ofrendas, Dintel de Kantatayita y Dintel

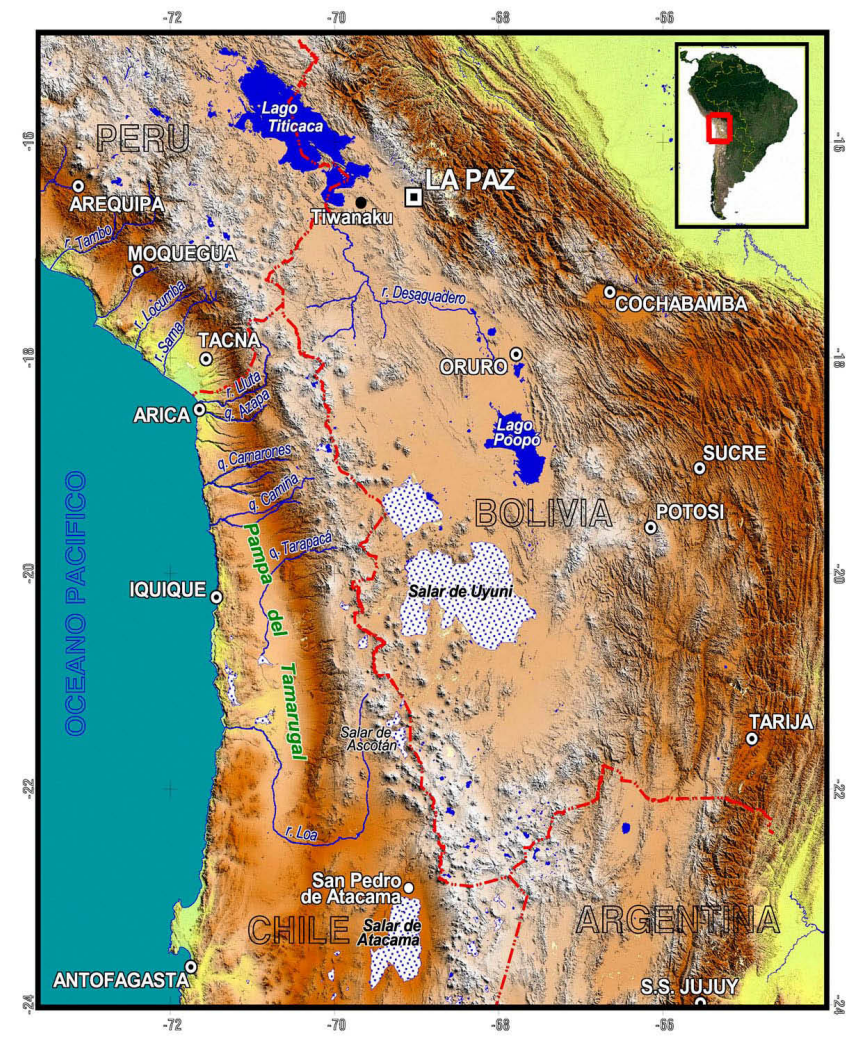

Figura 1. Mapa del área de influencia Tiwanaku en el que se indican los principales sitios mencionados en el texto (Agüero y Uribe 2018: 267, figura 1a).

de la calle Linares. En ellos se discriminaron cuatro niveles sucesivamente incluyentes de segregados: temas, figuras, motivos y elementos (Berenguer et al. 1998; Agüero et al. 2003) (Figura 2). Centrándonos en las tres principales figuras: Personaje Frontal, Personajes de Perfil y Banda-Faja, y los motivos presentes en ellas pudimos identificar motivos que tienen referentes en prendas textiles ayudando a determinar cuáles deben examinarse en las colecciones de la esfera Tiwanaku en Chile, Perú y Bolivia.

Oakland (1986) fue quien primero enfrentó los tejidos desde esta perspectiva, y definió el estilo textil relacionado a Tiwanaku a través de un análisis estilístico de 62 prendas encontradas en ocho sitios arqueológicos del Período Medio dentro del área de influencia de esta cultura altiplánica. El análisis de la iconografía, de la técnica, y en algunos casos, la consideración de los contextos - como en el caso 

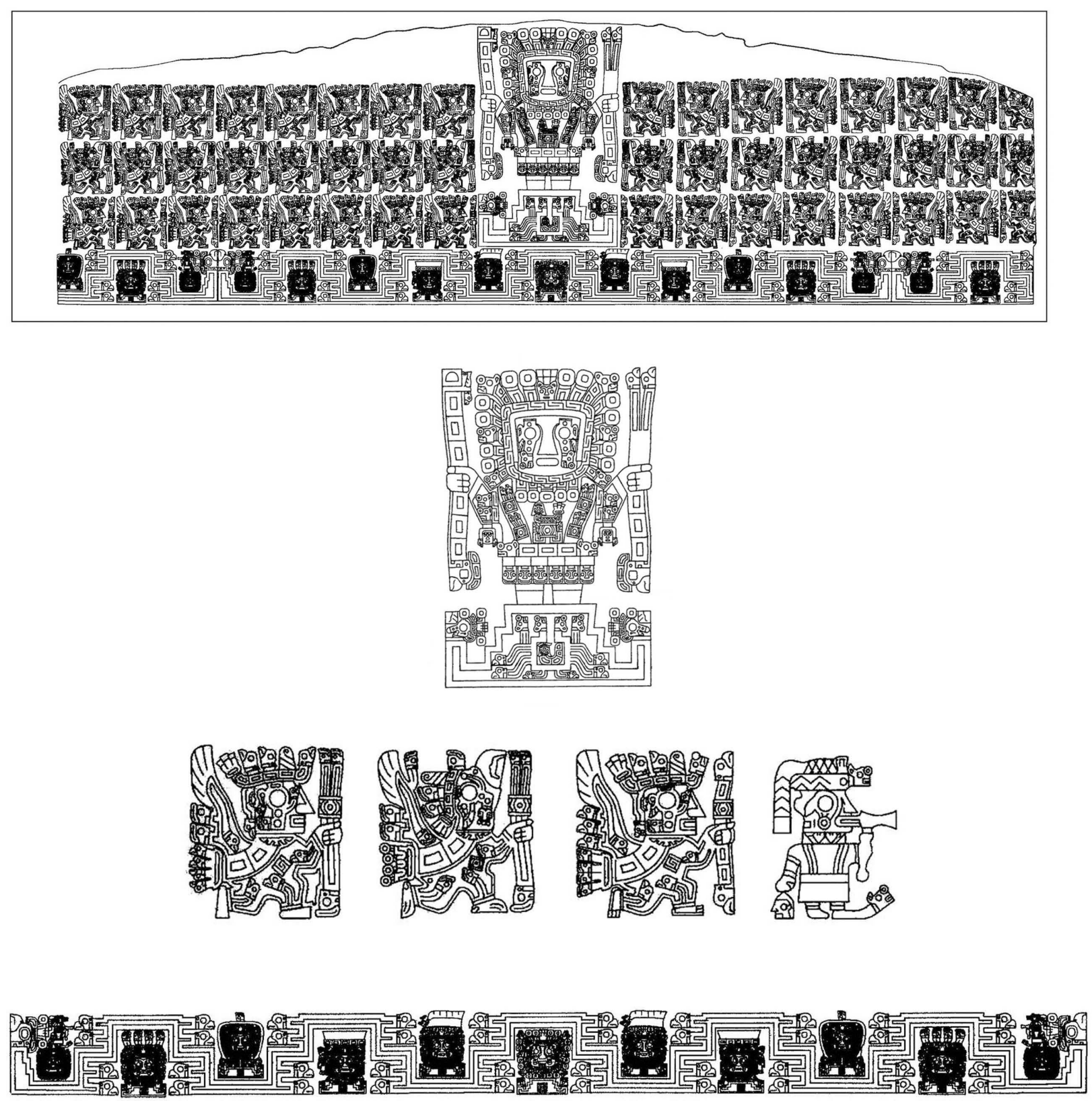

Figura 2. Tema Puerta del Sol y Figuras: Personaje Frontal, Personajes de Perfil y Banda Faja. Imagen basada en Posnansky 1946 Vol.I, Plates. XLV, XLVIa, y en Agüero et al. 2003: 8o, figuras 2, 3 y16.

de Coyo Oriente - podría identificar características formales compartidas con las esculturas líticas, ayudando a definir el estilo textil Tiwanaku el que contrastaría con los estilos, diseños y tecnologías locales. Las investigaciones de Ulloa (1982), Oakland (1986, 1986a, 1992, 1994), y las propias respecto a las tradiciones textiles locales (Agüero
1998, 2000) nos sirvieron de punto de partida para identificar los referentes textiles Tiwanaku; ya que se tuvo que identificar la textilería local - principalmente la de Arica y San Pedro - para segregarla de la Tiwanaku y poder explicar desde nuestra perspectiva las relaciones con la cultura altiplánica. 
Representaciones de textiles en los iconos de la litoescultura Tiwanaku y sus referentes en las colecciones arqueológicas

Las colecciones que estudiamos fueron las siguientes: Az1, Az-3, Az-13, Az-21, Az-103, Llu-51 (Colección Manuel Blanco Encalada); Az-6 (Focacci 1990), Az-71a (excavado por Focacci), Az-71b (Santoro 1980), Az-141 (excavado por Focacci) y PlM-9 (Focacci 1982) (Museo San Miguel de Azapa); Cementerio C (Tiwanaku) de Pisagua (Uhle 1919) (Museo Nacional de Historia Natural); Pica-8 (Instituto de Investigaciones Arqueológicas y Restauración Monumental de la Universidad de Antofagasta) (Zlatar 1984; Agüero 2015) y una prenda en el Museo Chileno de Arte Precolombino (Agüero y Uribe 2018); Tr-40B (Núñez 1981; Oakland 200o) entonces depositada en la Universidad Arturo Prat en Iquique; Coyo Oriente, Solcor-3, Quitor-2, Quitor-5 y Quitor-6 (Museo Arqueológico G. Le Paige, en San Pedro de Atacama); El Descanso y La Cruz (Minkes 2008) y Chiribaya
Baja (Clark et al. 1993) (Museo Chiribaya en Ilo), Algarrobal; M1 (Chen Chen) Cementerio (Vargas 1994 Ms.) (Museo Contisuyo, Moquegua); materiales exhibidos, sin referencia en el Museo Tiwanaku en La Paz y Tiwanaku, y en el Museo de Metales Preciosos en La Paz; Omereque y Mojocoya en el Museo Arqueológico de la Universidad Mayor de San Simón, Cochabamba y en el Museo Antropológico de la Universidad de San Francisco Xavier de Chuquisaca, Sucre. También pude dar un vistazo a la colección de Puqui (Oruro), una parte en el Museo Nacional de Etnografía y Folklore en La Paz, y otra en el Museo Arqueológico de la Universidad Mayor de San Simón en Cochabamba, aunque no hubo demasiado tiempo para hacer un registro sistemático. Finalmente, consideramos algunos textiles publicados por Ulloa (1982), Conklin (1983), Oakland (1986, 1986a), Goldstein (1989, 1990), Espoueys y coautores (1995), Wassén (1972), Strömberg (1956), Bird (1943) y Posnansky (1957).

En estas encontramos las siguientes prendas (Figuras 3 y 4):

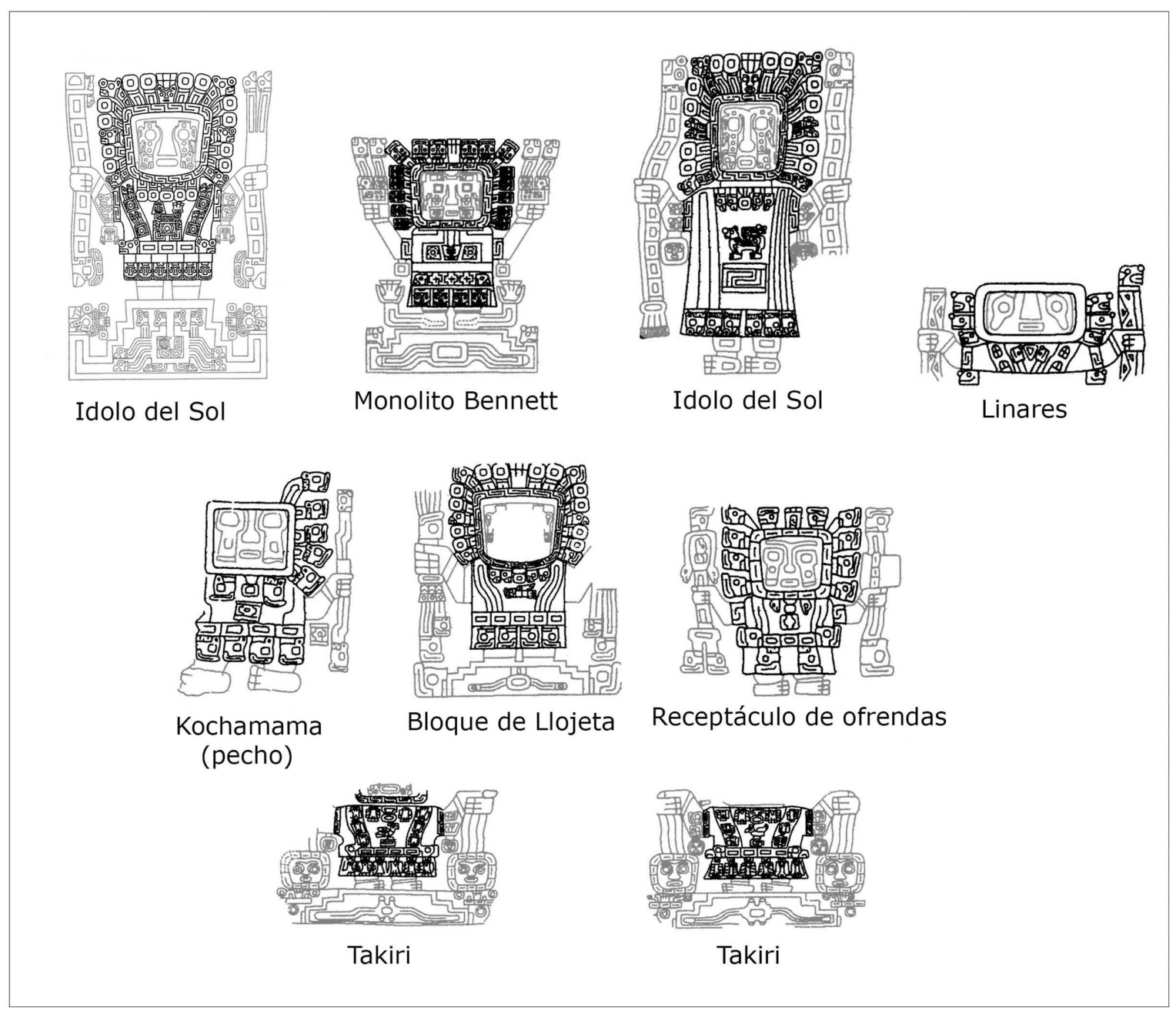

Figura 3. Personajes Frontales con sus túnicas y coronas. Adaptada de Agüero et al. 2003: 53, figura 2. 


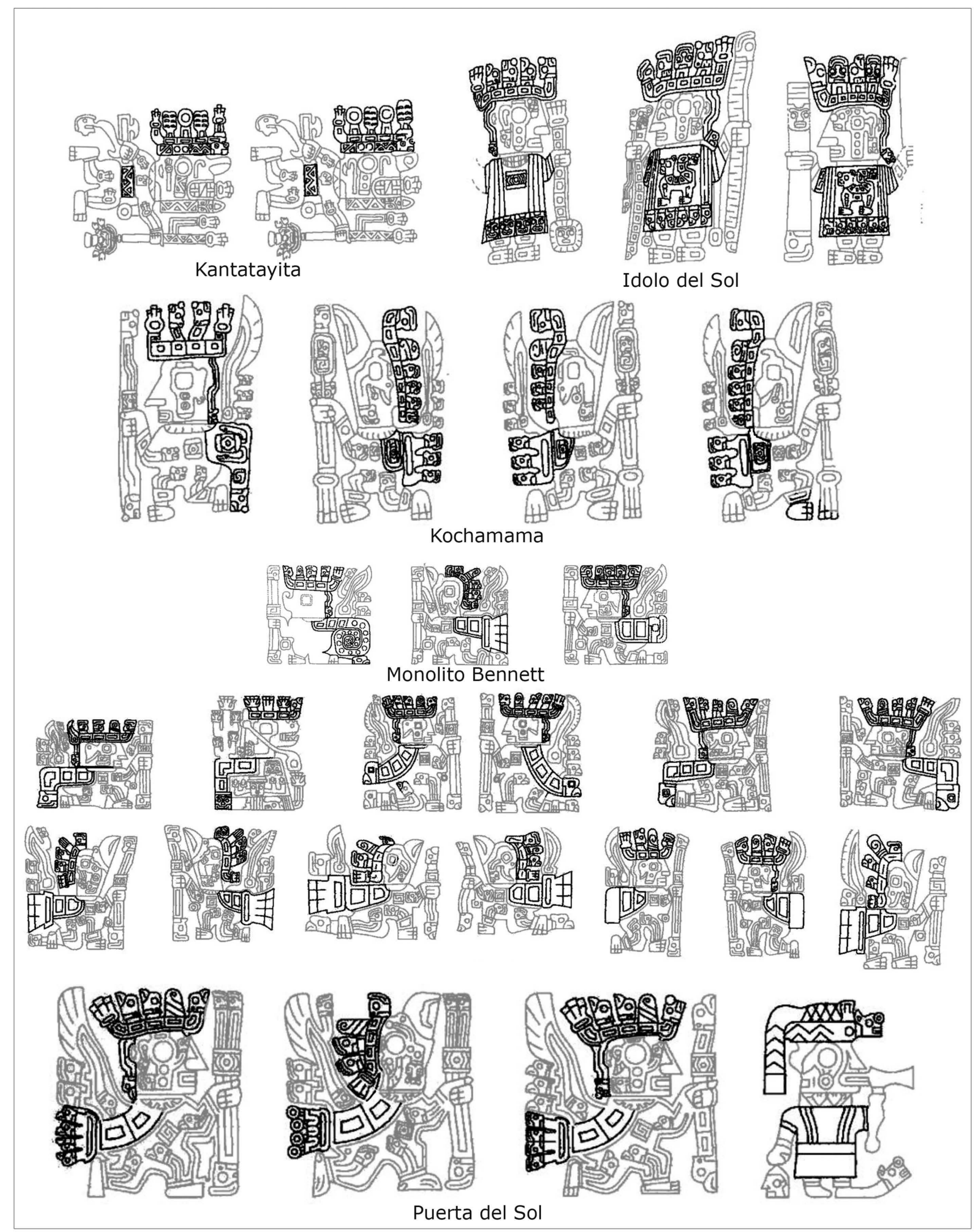

Figura 4. Personajes de Perfil con sus lauraques, bolsas y coronas. Solo los Personajes de Perfil del Idolo del Sol usan túnicas. Adaptada de Agüero et al. 2003: 54, figura 3. 
- Tocado: en los Personajes Frontales rodea la cara y está formado por un Marco facial, en tanto, en los Personajes de Perfil está constituido por una base con apéndices. Los monolitos llevan un tocado que ha sido identificado como de cintillo y casquete, por Oakland (1991) y Berenguer (1993). El tocado está presente en todos los personajes, tanto en los monolitos como en otros soportes líticos que tienen figuras frontales y de perfil, tanto humanas, animales y animalizadas, siendo un atributo de los seres vivos. Es interesante que estos tocados tienen representaciones de plantas "medicina" alucinógenas, como cebil o vilca (Anadenanthera colubrina), aguacoya o cactus San Pedro (Echinopsis pachanoi o Trichocereus pachanoi), así como un caracol de las tierras cálidas del oriente (Strophocheilus oblongus) (Figura 5).

Aunque también podrían tener forma de Bandas Cefálicas: En los Personajes Frontales se compone de los elementos Rectángulo con centro, o vacío, o cruz con/sin cabezas de pez, de aves de perfil o de felinos de perfil en sus extremos. No está en todos los soportes, faltando en el de Linares, Idolo del Sol y Lito de Takiri. En los Personajes de Perfil de
Kantatayita y Linares está representada vacía o con zigzag interior. En las colecciones textiles estas prendas no están puestas en un cuerpo, por lo que no se sabe si se trata de fajas o bandas cefálicas por lo que Uribe (1998) denominó "Bandas Faja" (Figura 6 y 7) a la sucesión horizontal de figuras intercaladas por un meandro o línea sinuosa. Esta adopta tres expresiones, pudiendo aparecer a) en forma independiente sin funcionalidad alguna (Receptáculo lítico de ofrendas), b) insinuando su uso como base o plataforma para figuras antropomorfas (Puerta del Sol y de la Luna), c) cumpliendo explícitamente la función de faja en lo que sería la vestimenta de los monolitos Ponce, Bennett, Kochamama, El Fraile, Idolo Plano e Idolo de Puno (Figura 8). Arturo Martínez piensa que se trata de la representación de cómo se manifiesta la ayahuasca en los (Banisteriopsis caapi), en los rituales en que se consume, es decir, de forma serpentiforme (Figura 9).

Aparte de lo anterior, se observan fajas propiamente tales en los Personajes Frontales, compuestas de elementos como rectángulo con centro, o vacío, o cruz con/sin cabezas de

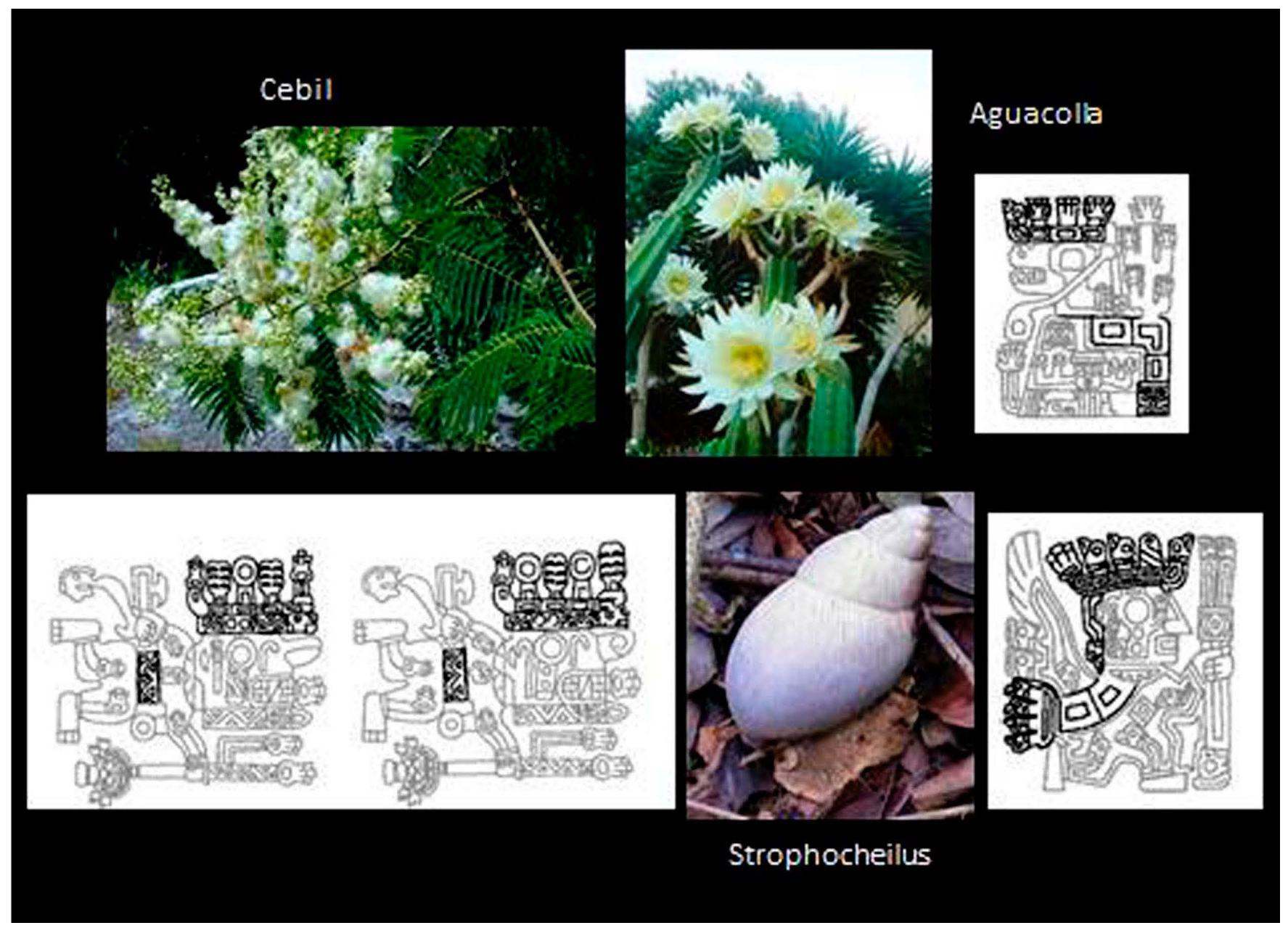

Figura 5. Representación de "plantas medicina o maestras" en algunos iconos. Imágenes producidas por Proyecto FONDECYT 1970073. 


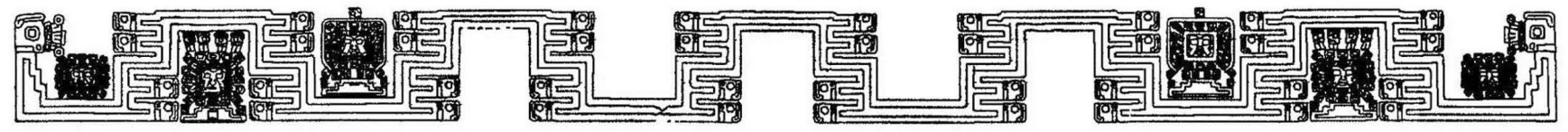

Puerta del la Luna

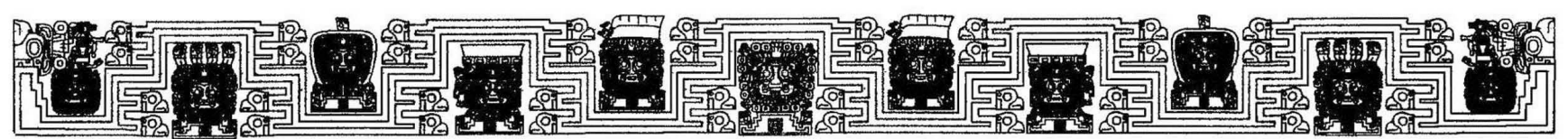

Puerta del Sol
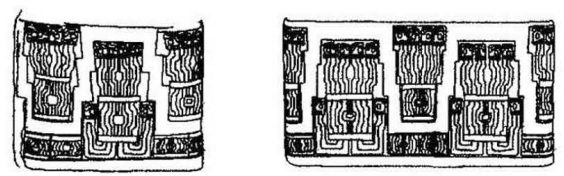

Kochamama

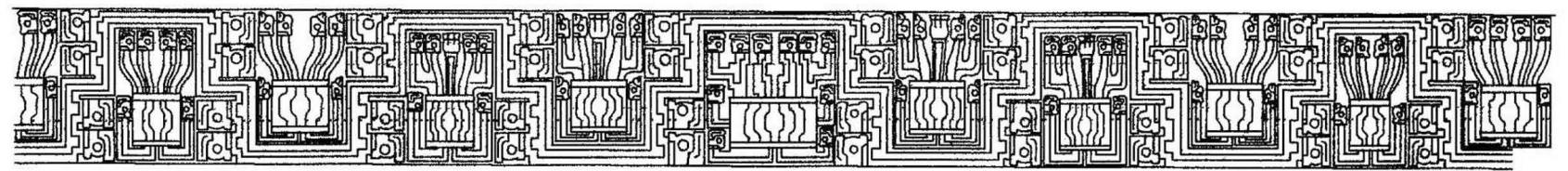

Bennet

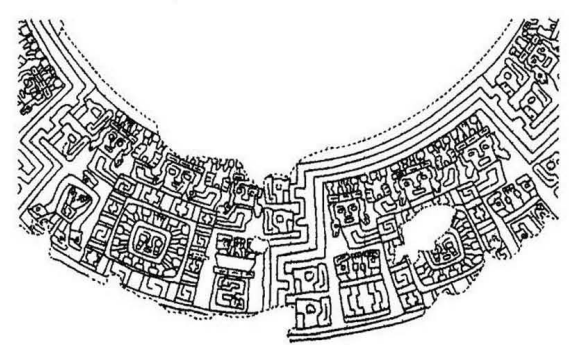

Receptáculo Lítico de Ofrendas

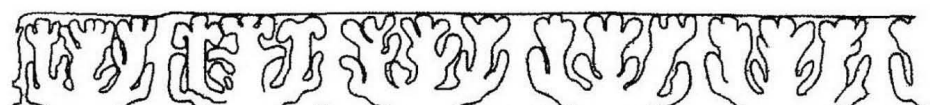

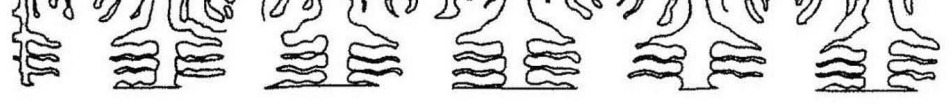

El Fraile

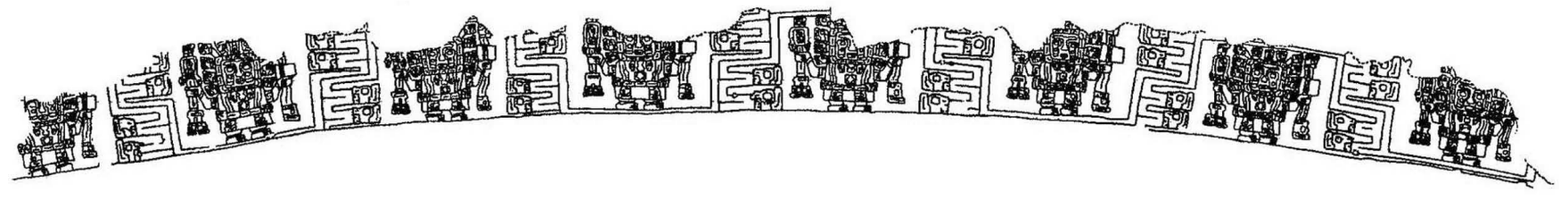

Receptáculo Litico de Ofrendas

Figura 6. "Bandas fajas" o meandros (Agüero et al. 2003: 68, figura 5). 


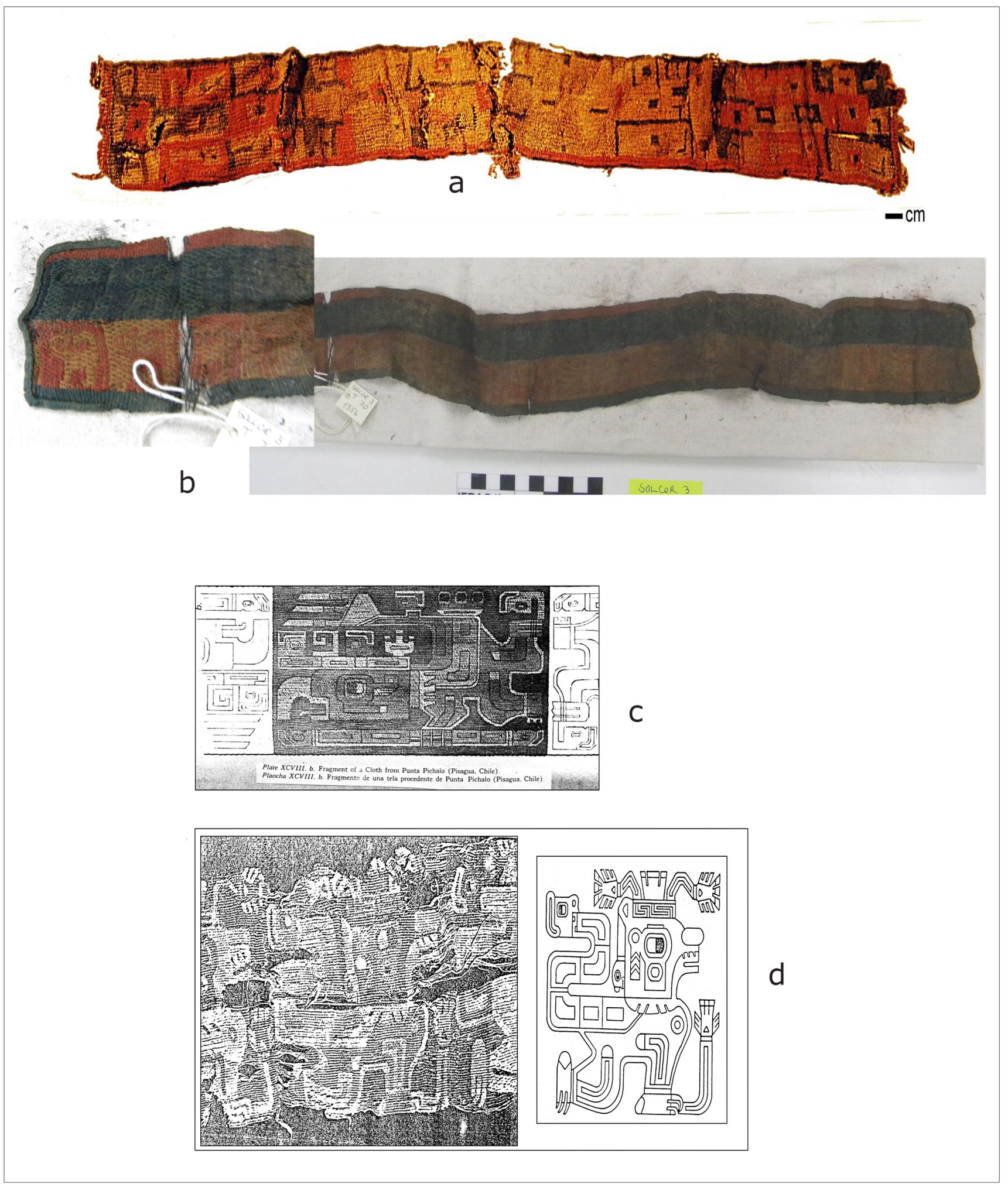

Figura 7. Bandas cefálicas: a y b) San Pedro de Atacama (fotografías de la autora, en Agüero y Uribe 2014: figura 5); c) Pisagua: ave (tomada de Posnansky 1957: Plate XCVIII); d) Pisagua: felino (tomada de Conklin 1983: 39, figura 34). 


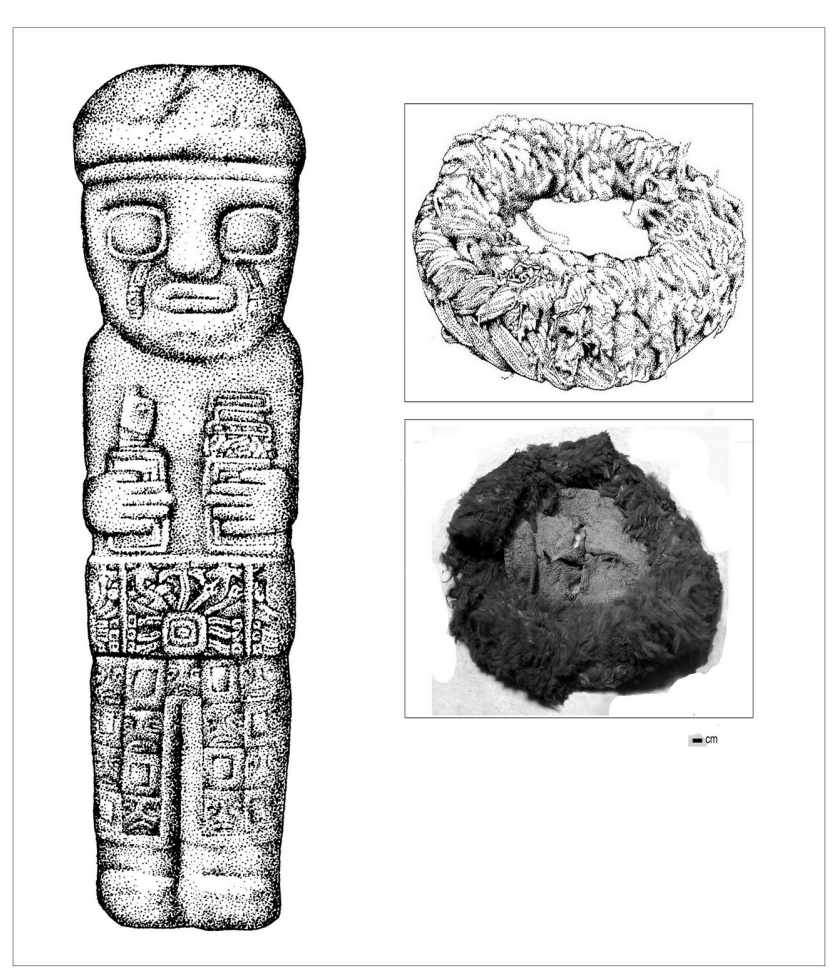

Figura 8. Estatuilla de Puno, y gorros de cintillo y casquete de San Pedro de Atacama. Imágenes producidas por Proyecto FONDECYT 1970073 basadas en Berenguer 1987: 42, figura 9; y en fotografías de la autora.

pez, de aves de perfil o de felinos de perfil en sus extremos. En los Personajes de Perfil más tempranos muestran un atributo de felino (Pucara), y en los dinteles de Kantatayita y Linares, la faja está vacia o con zigzag interior. Pero no se encontraron los referentes artefactuales.

Otra prenda identificada fue la Túnica: está formada por franjas y orillas inferiores (con cabezas de felinos frontales o de perfil, o cabezas de pez o de ave), y orillas laterales (vacías o con grecas o cabezas de ave, de pez o de felino de perfil). Se observa en los monolitos y portadas, y en todos los Personajes Frontales, pero sólo en algunos Personajes de Perfil del Idolo del Sol y Puerta del Sol tratándose, al parecer, de una prenda propia de los seres humanos, o que "humaniza". La Franja siempre está vacía en los Personajes de Perfil (siendo listas lisas), lo que no ocurre siempre en los Personajes Frontales. Las túnicas con Franja compuesta por motivos, parecen corresponder a aquellas tejidas en tapicería (Figura 10).

Por otra parte, la Bolsa: que puede estar formada por el elemento "bolsa" (convención), por un rectángulo, o por una gran cabeza de ave, pez o felino de perfil; los flecos (cuando hay) por apéndices con círculos, o cabezas de ave, pez o felino de perfil; el tirante por rectángulos con centro, o con greca. La bolsa la encontramos únicamente en ciertos

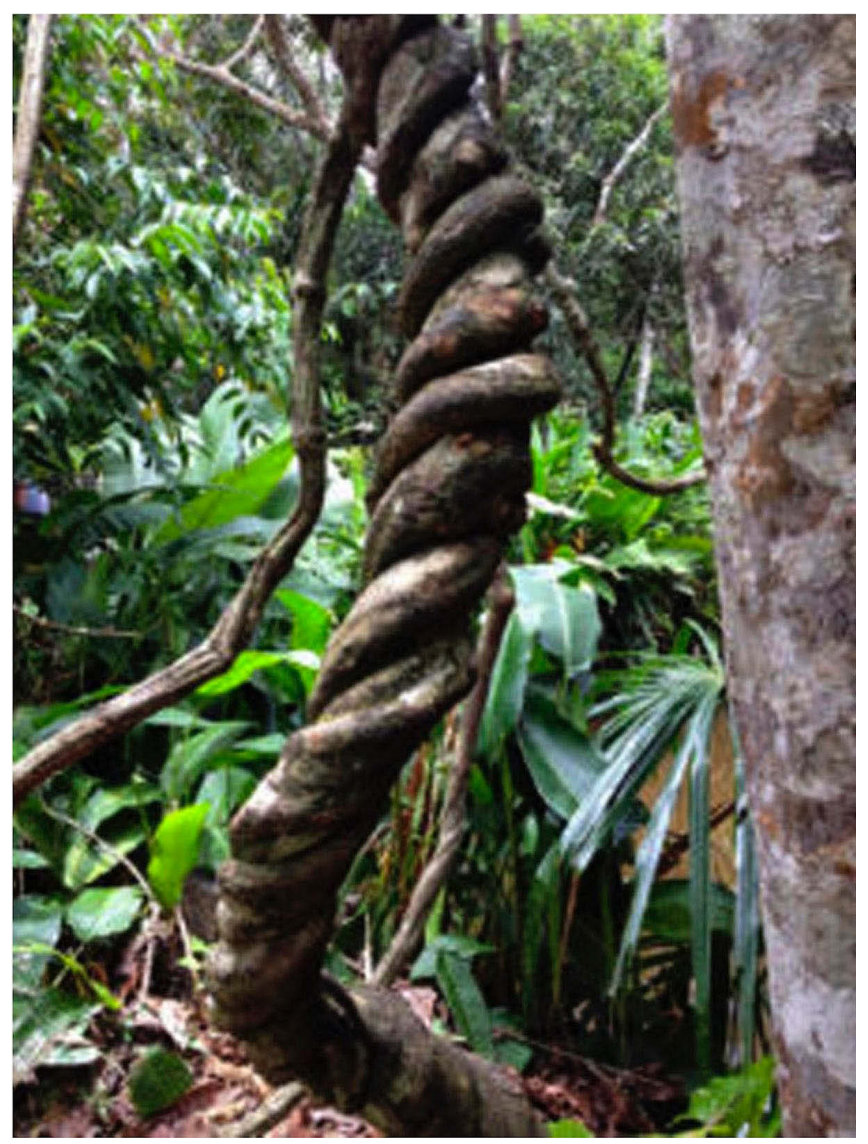

Figura 9. Ayahuasca o "abuela" (Banisteriopsis caapi) (ver Figura 6). Tomada de https://articulo.mercadolibre.com.mx/ MLM-666919007-ayahuasca-miel-pasta-500-gr-_JM

Personajes de Perfil (los Antropomorfos "ornitomorfizados"), es decir, los que integran algunos atributos anatómicos pertenecientes a las aves, tales como: ala, cabeza de ave y garras en una posición que se relaciona con el consumo de sustancias psicoactivas (según Berenguer 1987). Estos personajes se encuentran en Kochamama, Monolito Bennett y en la Puerta del Sol, en la cual tienen su parte inferior dentada y muestran estrechas similitudes con aquellas de estilo Wari registradas en el sur de Perú (Taullard 1949; Vanstan 1969). Resulta de interés que todos los personajes "ornitomorfizados" compartan la representación de la bolsa, que usada cruzando el cuerpo se asocia a viajes, y que eventualmente podríamos asociar a hombres medicina itinerantes, como los kallawaya del altiplano boliviano que actualmente llegan hasta Camiña en la región de Tarapacá (norte de Chile). Además de la posición anatómica, exhiben artefactos asociados a sustancias psicoactivas, como tableta, y por supuesto, las bolsas que las contendrían así como al resto de la parafernalia necesaria (Berenguer 1987). Lo anterior es reforzado por Oakland (1986) quien observa que tres bolsas de Niño Korín (Wassén 1972) contenían hojas de 


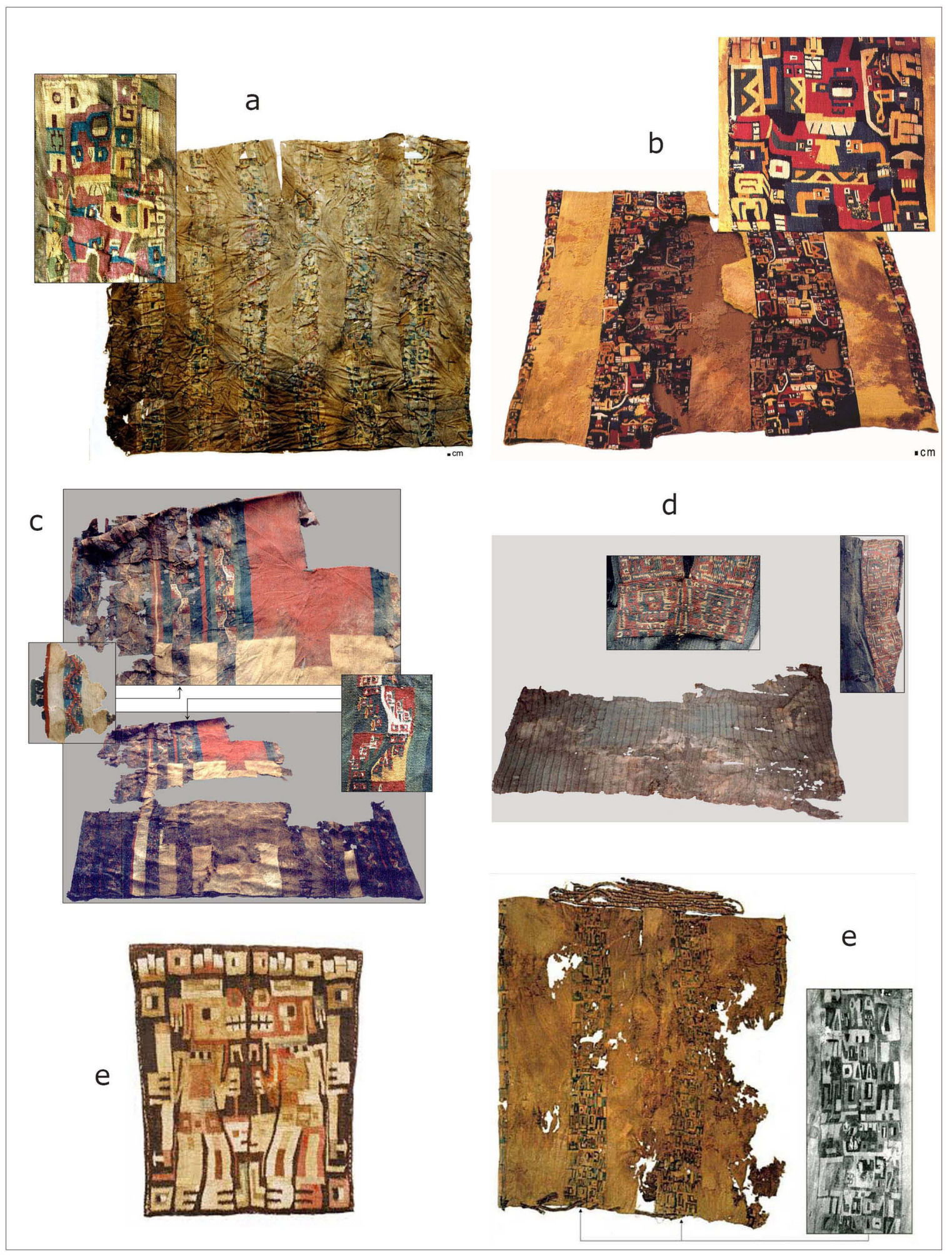

Figura 10. a) Túnica de San Pedro de Atacama con representaciones de aves de perfil (Agüero 2012: 42, figura 10; b) Túnica de Pulacayo con representaciones de Personajes de Perfil antropomorfos con colmillos de felino (Agüero 2007: 90, figura 7); c) Túnica de Tarapacá-40 con representación de la Banda Faja de la Puerta del Sol (Agüero y Uribe 2018: 271, figura 10.2); d) Túnica de Tarapacá-40 con representaciones bordadas de Personajes de Perfil antropomorfos (Agüero y Uribe 2018: 272, figura 10.3); e) Túnica procedente de Boca del río Osmore con representaciones de Personajes de Perfil antropomorfos con rostros de felino (tomada de Minkes 20o8: figura 5); f) Túnica de Pica-8 con representaciones de Personajes de perfil antropomorfos felinizados (Agüero y Uribe 2018: 272, figura 10.4). 
Ilex Guayusa, y recientemente por Miller y coautores quienes analizan el fardo de un niño encontrado en el altiplano de Lípez (Bolivia) hallando por primera vez evidencias del uso de múltiples plantas psicoactivas como ayahuasca, coca (Erythroxylum coca), tabaco (Nicotiana spp.) y cebil, tal como se observa en la iconografía que analizamos en este trabajo. En las colecciones encontramos bolsas como las de

\section{la Figura 11.}

Inkuñas y mantas: no han sido identificadas en la litoescultura, pero creemos que ciertas prendas de sitios arqueológicos del Período Medio en el norte de Chile, sur del Perú, altiplano y valles orientales de Bolivia, corresponden a textiles Tiwanaku, y son importantes de mencionar porque muestran patrones distribucionales diferenciales en las áreas consideradas.

\section{Discusión y conclusiones: patrones de distribución espacial de la iconografía y su probable significado}

Con la excepción de colecciones como Niño Korín (Wassén 1972) y Manzanani, Omereque, Mojocoya y Pérez (Strömberg 1956; Oakland 1986), la mayoría de los textiles con imágenes Tiwanaku se ha registrado en la costa o en los oasis del norte de Chile y sur de Perú (Conklin 1983; Oakland 1986, 1987, 1992, 2000; Berenguer y Dauelsberg 1989; Minkes 2008; Baitzel y Golstein 2014, Sharrat 2014).

Según los datos recogidos en los Valles Occidentales, Altiplano, Valles Orientales de Bolivia, y Atacama, los textiles y la iconografía, difieren en dos grandes áreas: al Oeste y Este de los Andes, y por lo tanto, suponemos que las motivaciones y el tipo de relaciones establecidas por Tiwanaku, con ellas.

Comprobamos que, en general, en los textiles se representan figuras de Personajes de Perfil Antropomorfos y Zoomorfos, siguiendo, al igual que en la litoescultura, ciertos principios, como el de repetición, simetría en espejo y el de jerarquía (este último, si consideramos que es sólo el Personaje Frontal quien usa túnica, con la única excepción de los Personajes de Perfil del Idolo del Sol).

Hasta el momento, gran parte de la iconografía figurativa de los textiles Tiwanaku se relaciona con aquella de los soportes líticos de todas las fases de la secuencia estilística planteada por Isbell y Cook (1987) y por Agüero y coautores (2003), pero especialmente con Tiwanaku III-IV. Aquella se ajusta casi por completo a las representaciones de Personajes de Perfil y Meandros de la litoescultura, siendo los primeros los que se privilegian para ser plasmados en túnicas, bolsas, inkuñas, fajas o bandas cefálicas y mantas. Estos son los tejidos que llegan a todas las zonas estudiadas, pero, en mayor cantidad a San Pedro de Atacama.
También pudimos observar algo de gran interés, y es que los Valles Occidentales concentran de manera exclusiva a las figuras de perfil de camélidos y felinos, a los Personajes de Perfil Antropomorfos y Antropomorfos Felinizados, en tanto, la vertiente más oriental y centro sur tienen exclusividad sobre las figuras de aves (ya sea aves de perfil volando y pedestales y meandros terminados en cabezas de aves con tocado), cobrando especial relevancia la presencia de Personajes de Perfil Antropomorfos Ornitomorfizados frente a la ausencia total de Personajes de Perfil Antropomorfos Felinizados.

También hay una relación entre el tipo de prendas y la iconografía registrada. Las prendas de los Valles Occidentales relacionadas a camélidos y felinos son bastante más "prácticas" que las del Este y Centro Sur de los Andes ya que predominan las túnicas con bordados. Del otro lado, las aves se relacionan a prendas rituales como las bolsas. En efecto, las aves en vuelo y las cabezas de ave coronadas unidas a escalerados o meandros se observan principalmente en bolsas, orillas de mantas, una banda faja, y una inkuña o manta de San Pedro. Estas prendas aparecen con otras con iconografía del Idolo del Sol (Personajes de Perfil Antropomorfos y Personajes Frontales) en túnicas con tapicería o faz de trama en la parte inferior imitando las túnicas de esos personajes.

En suma, en Bolivia y Atacama (en el norte de Chile) se aprecia una relación entre las bolsas, y la iconografía de aves y personajes antropomorfos con atributos de aves, lo que resulta coherente con que, en la litoescultura, la bolsa se representa únicamente en los Personajes de Perfil Antropomorfos con atributos de aves, como ala, cabeza y garras, y también una posición que se relaciona con el consumo de sustancias psicoactivas (Berenguer 1987). Esto se refuerza al ver que tres bolsas de Niño Korín contenían hojas de Ilex Guayusa, y que en toda esta zona de Valles Orientales, Altiplano Meridional y Atacama los artefactos del llamado “complejo alucinógeno" son frecuentes en los contextos funerarios (Horta 2014).

Por otro lado, en Cochabamba con la ausencia de textiles tanto Tiwanaku III-IV y V, y la presencia de textiles Tiwanaku Provincial (sensu Oakland 1986) se ve que algunos elementos de estilo Tiwanaku se reinterpretan con bastante libertad sugiriendo que aquí no habría población Tiwanaku asentada pero que ya habían relaciones establecidas con la cultura altiplánica, las que habrían sido de naturaleza diferente a las mantenidas con los Valles Occidentales, y nunca tan directas.

En suma, Tiwanaku temprano (III-IV) habría accedido a todas las zonas consideradas, pero introduciendo de manera diferencial prendas e iconografía en las subáreas AltiplanoValles Occidentales y Valluna-Circumpuneña (Figura 12). Es así como observamos tendencias en las representaciones 


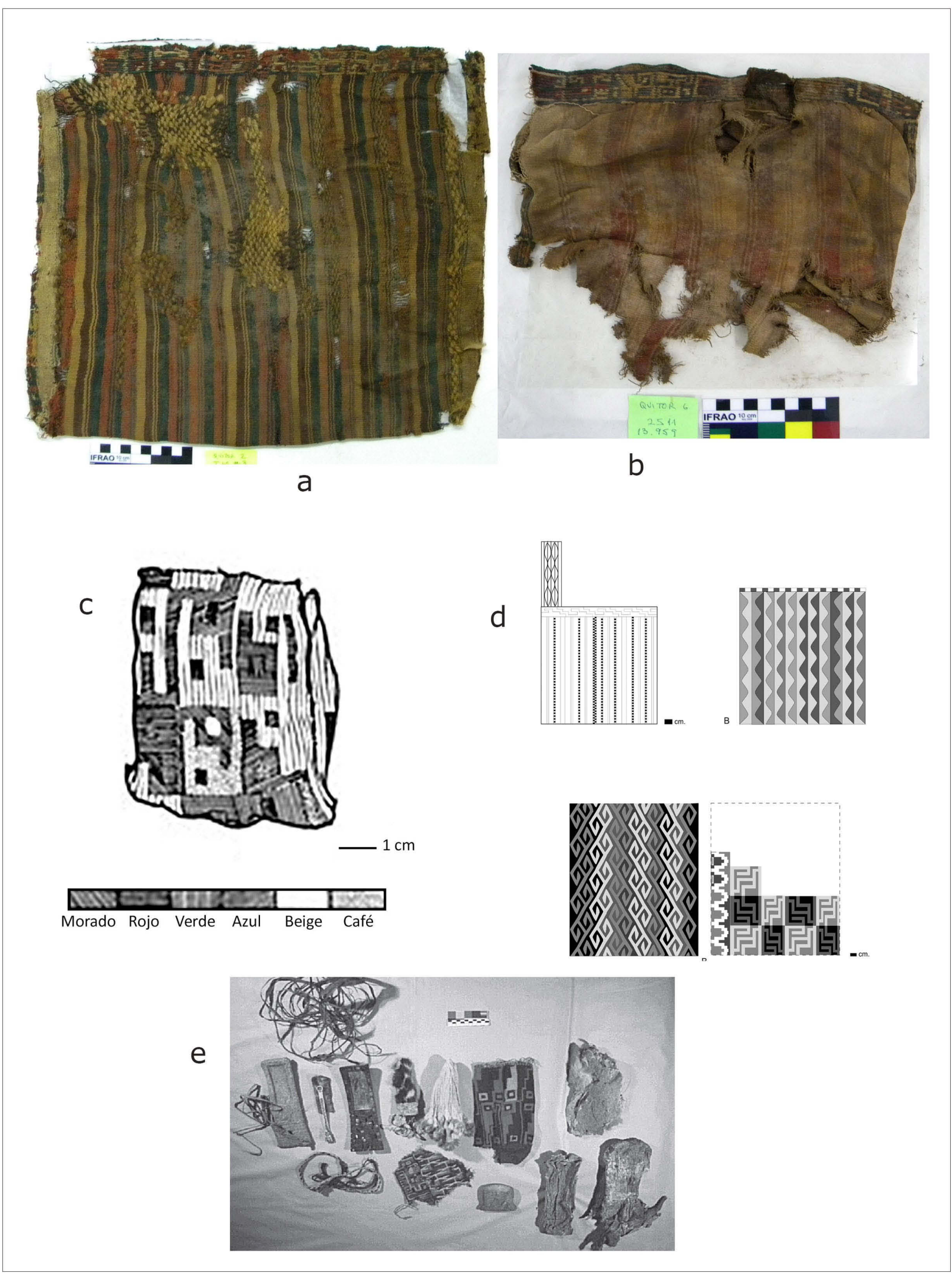

Figura 11. a y b) Bolsas de San Pedro de Atacama con bordados superiores con representaciones de aves (fotografías de la autora); c) Bolsa de Los Verdes (Región de Tarapacá) (dibujo de Paulina Chávez encargado por la autora); d) Bolsas de los valles cochabambinos (dibujo de Paulina Chávez encargado por la autora); e) Bolsa del conjunto de Amaguaya (tomado de Capriles 2002 (23):35, figura 2). 


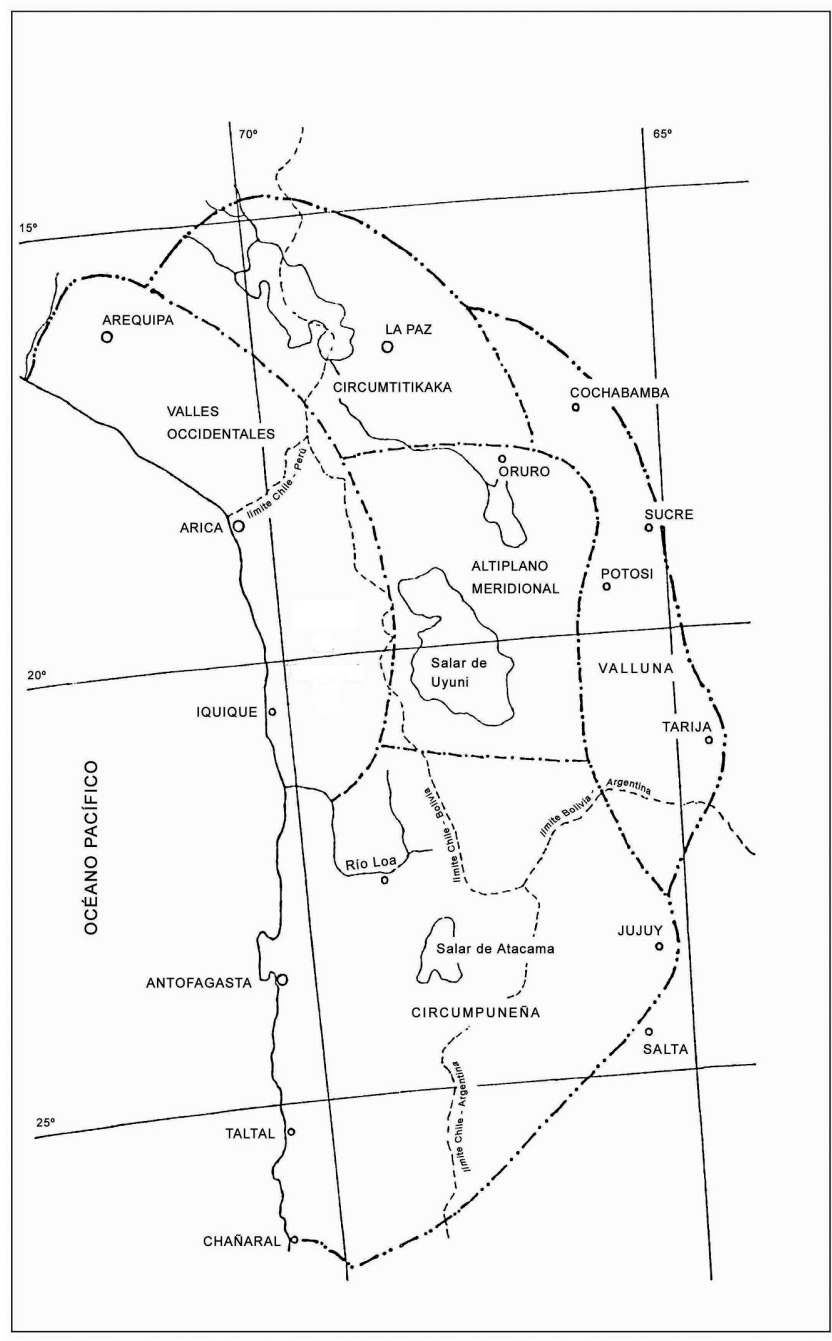

Figura 12. Mapa del Área Centro Sur Andina, en el cual se señalan las subáreas mencionadas en el texto. Adaptado de Núñez 1984 y publicado por Agüero 2015: 39, figura 1).

iconográficas (siempre de figuras de perfil) de felinos y humanos felinizados principalmente en túnicas de los Valles Occidentales, y aves y humanos ornitomorfizados en el Altiplano Meridional y en Atacama, principalmente en bolsas y túnicas de contextos relacionados con artefactos del "complejo alucinógeno", asociación que sugiere que estas últimas áreas parecen haber sido exploradas con intereses en aspectos rituales vinculados con el consumo de plantas maestras o plantas medicina.

Por su parte, la expresión textil Tiwanaku V está presente únicamente en los valles cochabambinos y en los Valles Occidentales, y se vincula a la producción de prendas de estilo Tiwanaku Provincial. Este último, contemporáneo a Tiwanaku $\mathrm{V}$ tiene principalmente dos centros de producción: Moquegua y Cochabamba. Ambas zonas evidencian, eso sí, relaciones diferentes con Tiwanaku, mientras en Moquegua la relación es directa, en Cochabamba es indirecta a juzgar por la libertad con que se toman y reinterpretan los programas textiles Tiwanaku. En Moquegua, salvo excepciones (p.e. Baitzel y Golstein 2014, Sharrat 2014) estos textiles son "cotidianos", están muy reparados, son monócromos o con listas de colores y como decoración a lo más presentan bordados geométricos (meandros, escalerados, ganchos, rectángulos con centro, entre otros) en las uniones laterales y orillas. La presencia de población Tiwanaku establecida en Moquegua explica la existencia de estas prendas "comunes y corrientes" carentes de iconografía figurativa o compleja, siendo durante esta fase que surgen los textiles en primera instancia catalogados como Tiwanaku Provincial, ya que los soportes son fabricados localmente. Se puede apreciar una iconografía tardía distinta a los referentes líticos, y vinculada a técnicas locales producto de la interacción persistente con las poblaciones cercanas al Pacífico.

En suma, en este trabajo observamos tendencias en la distribución de las prendas textiles y su iconografía lo que, sin duda, no es azarozo, sino que tiene un significado; esta proposición fue posible gracias al trabajo en colaboración con un hombre-medicina. Esperamos que este esfuerzo constituya un aporte para que en el futuro se desarrollen otras investigaciones con nuevas líneas interpretativas.

\section{Bibliografía}

Agüero, Carolina

1998 Tradiciones Textiles de Atacama y Tarapacá Presentes en Quillagua Durante el Período Intermedio Tardío. Boletín del Comité Nacional de Conservación Textil 3: 103-128.

Agüero, Carolina

2000 Las Tradiciones de Tierras Altas y de Valles Occidentales en la Textilería Arqueológica del Valle de Azapa. Chungara 32(2): 217-225.

Agüero, Carolina

2001 Ms. Textiles e Iconografía Tiwanaku: Patrones Distribucionales en Zonas de Frontera. Manuscrito en poder de la autora.

Agüero, Carolina

2007 Los Textiles de Pulacayo y la Relaciones entre Tiwanaku y San Pedro de Atacama. Boletín del Museo Chileno de Arte Precolombino 12(1): 85-98.

Agüero, Carolina

2012 Desarrollo de los Textiles Prehispánicos de la Región Atacameña. Canto Rodado 7: 29-54.

Agüero, Carolina

2015 Vestuario y Sociedad Andina, C. Agüero (Editora). Pp. 256. Santiago: Qillqa Ediciones. 
Agüero, Carolina y Mauricio Uribe

2014 Rethinking the Tiwanaku Phenomenon in San Pedro de Atacama Through the Study of Textiles of Solcor 3 and Their Associated Contexts (400-100o AD). 9-2014. Proceedings Textile Society of America. DigitalCommons@University of Nebraska - Lincoln

Agüero, Carolina y Mauricio Uribe

2018 Tiwanaku in the Tarapacá Region (Chile): ¿Realities or Illusions in the Desert? En Images in Action: The Southern Andean Iconographic Series. W. Isbell et al. (Editores). Pp. 261-286. Los Angeles: Cotsen Institute of Archaeology Press.

Agüero, Carolina, Mauricio Uribe y José Berenguer

2003 La Iconografía Tiwanaku: El Caso de la Escultura Lítica. Textos Antropológicos 14(2): 47-82.

Baitzel, Sarah y Paul Goldstein

2014 More than the Sum of its Parts: Dress and Social Identity in a Provincial Tiwanaku Child Burial. Journal of Anthropological Archaeology 35(1): 51-62.

Bennett, Wendell

1946 The Archaeology of the Central Andes. Handbook of South American Indians, J. Steward (Editor). Vol. II: 599-618. Washington D.C.

Berenguer, José

1987 Consumo Nasal de Alucinógenos en Tiwanaku: Una Aproximación Iconográfica. Boletín del Museo Chileno de Arte Precolombino 2: 33-53.

Berenguer, José

1993 Gorros, Identidad e Interacción en el Desierto Chileno antes y después del Colapso de Tiwanaku. En Identidad y Prestigio en los Andes: Gorros, Turbantes y Diademas. Catálogo de Exposición, pp: 31-64. Santiago: Museo Chileno de Arte Precolombino.

Berenguer, José

1998 Una Exploración de la Iconografía del Poder en Tiwanaku y su Rol en la Integración de Zonas de Frontera. Informe de Avance. Boletín de la Sociedad Chilena de Arqueología 26: 3.

Berenguer, José y Percy Dauelsberg

1989 El Norte Grande en la Órbita de Tiwanaku. En Culturas de Chile. Prehistoria, J. Hidalgo et al. (Editores). Pp. 129-180. Santiago: Editorial Andrés Bello.

Bird, Junius

1943 Excavations in Northern Chile. Anthropological Papers of American Museum of Natural History, New York.

Capriles, José

2002 Intercambio y Uso Ritual de Fauna por Tiwanaku: Análisis de Pelos y Fibras de los Conjuntos Arqueológicos de Amaguaya, Bolivia. Estudios Atacameños 23: 33-51

Clark, Nikki, F. Palacios y Nilda Juárez

1993 Ms. Proyecto Textil Chiribaya Baja: Cementerio 1. Fardos y Textiles. Informe preliminar.
Conklin, William

1983 Pucara and Tiahuanaco Tapestry: Time and Style in a Sierra Weaving Tradition. Nawpa Pacha 21: 1-33.

Conklin, William

1991 Tiahuanaco and Huari: Architectural Comparison and Interpretations. En Huari Administrative Structure, W. Isbell y G. McEwan (Editors). Pp. 281-291. Washington D.C.: Dumbarton Oaks

Cordy-Collins, Alana

1976 An Iconographic Study of Chavin Textiles from the South Coast of Peru: The Discovery of a PreColumbian Catechism. Ph.D. Diss., University of California, Los Angeles.

Espoueys, Oscar, Helena Horta y Vivian Reciné

1995 Estudio de una Pieza Textil de Filiación Tiwanaku del Valle de Azapa, Arica, Chile. Boletín del Museo Chileno de Arte Precolombino 6: 111-125.

Focacci, Guillermo

1982 Excavaciones en el Cementerio Playa Miller 9. En Documento de Trabajo 2, I. Muñoz y G. Focacci (Editores). Pp. 126-214. Arica: Universidad de Tarapacá.

Focacci, Guillermo

1990 Excavaciones Arqueológicas en el Cementerio Az-6. Valle de Azapa. Chungara 24-25: 7-55.

Goldstein, Paul

1989 Omo, a Tiwanaku Provincial Center in Moquegua, Perú. Ph.D. Diss., Dept. of Anthropology, University of Chicago, Illinois.

Goldstein, Paul

1990 La Ocupación Tiwanaku en Moquegua. Gaceta Arqueológica Andina V(18-19): 75-104.

Horta, Helena

2014 Lo Propio y lo Ajeno. Definición del Estilo San Pedro en la Parafernalia Alucinógena de los Oasis del Salar de Atacama. Chungara, Revista de Antropología Chilena 46(4): 559-583

Miller, Melanie, Juan Albarracín Jordán, Christine Moore y José Capriles

2019 Chemical Evidence for the Use of Multiple Psychotropic Plants in a 1,0oo-Year-Old Ritual Bundle from South America. PNAS June 4, 2019116 (23) 11207-11212; first published May 6, 2019 https://doi.org/10.1073/pnas.1902174116

Minkes, Wynne

2008 Warp the Loom-Wrap the Dead. Trapezoidal Shaped Textiles from the Chiribaya Culture, South Peru, AD 90o-1375. En Textiles as Cultural Expressions: Proceedings of the 11th Biennial Symposium of the Textile Society of America, September 24-27, Honolulu.

Museum of Primitive Art

1965 Ancient Peruvian Textiles from the Collection of The Textile Museum Washington D.C. New York. 
Núñez, Lautaro

1981 Emergencia de Sedentarización en el Desierto Chileno: Subsistencia Agraria y Cambio SocioCultural. Revista Creces II.

Núñez, Lautaro

1984 Tráfico de Complementariedad de Recursos entre las Tierras Altas y el Pacífico en el Área Centro Sur Andina. Tesis Doctoral, Departamento de Antropología Cultural, Universidad de Tokyo, Tokyo.

Oakland, Amy

1981 Ms. Tejidos Preincaicos en Cochabamba. Museo Arqueológico de la Universidad Mayor de San Simón, Cochabamba.

Oakland, Amy

1986 Tiwanaku Textile Style from the South Central Andes, Bolivia and North Chile. Ph.D. Diss., University of Texas, Austin.

Oakland, Amy

1986a Tiwanaku Tapestry Tunics and Mantles from San Pedro de Atacama, Chile. En The Junius Bird Conference on Andean Textiles, A. Rowe (Editor). Pp. 101-122. Washington D.C.: The Textile Museum.

Oakland, Amy

1992 Textiles and Ethnicity: Tiwanaku in San Pedro de Atacama, North Chile. Latin America Antiquity 3(4): 316-340.

Oakland, Amy

1994 Tradición e Innovación en la Prehistoria Andina de San Pedro de Atacama. Estudios Atacameños 11: 109-120.

Oakland, Amy

2000 Andean Textiles from Village and Cemetery: Caserones in the Tarapacá Valley, North Chile. En Beyond Cloth and Cordage, P. Drooker y L. Webster (Editors). Pp. 229-251. Salt Lake City: University of Utah Press.

Posnansky, Arthur

1945 Tihuanacu, la Cuna del Hombre Americano. Vols I y II. New York: Augustin Publishers.

Posnansky, Arthur

1957 Tihuanacu, la Cuna del Hombre Americano. Vols. III y IV. La Paz: Ministerio de Educación.

Proyecto FONDECYT 1970073

1997-200o. Una Exploración de la Iconografía del Poder en Tiwanaku y s Una Exploración de la Iconografía del Poder en Tiwanaku y su Rol en la Integración de Zonas de Frontera. A cargo de José Berenguer.
Santoro, Calogero

1980 Estudio de un Yacimiento Funerario Arqueológico del Extremo Norte de Chile, 1300 AC-130o DC. Tesis para optar al Título de Arqueólogo, Depto. de Arqueología, Universidad del Norte, Antofagasta.

Simileld, Katrina

1981 Ms. La Colección de los Tejidos de Puqui. Museo Arqueológico de la Universidad Mayor de San Simón, Cochabamba.

Stromberg, Elizabeth

1956 Textile Fragments from a Burial Cave at Pérez, Mizque Valley, Bolivia. En The Erland Nordenskiöld Archaeological Collection from the Mizque Valley, Bolivia (Stig Rydén). Etnologiska Studier 22, Etnografiska Museet, Göteborg.

Taullard, Alfred

1949 Tejidos y Ponchos Indígenas de Sudamérica. Buenos Aires: Editorial Guillermo Kraft Ltda.

Uhle, Max

1919 La Arqueología de Arica y Tacna. Boletín de la Sociedad Ecuatoriana de Estudios Históricos Americanos 7-8.

Ulloa, Liliana

1982 Estilos Decorativos y Formas Textiles de Poblaciones Agromarítimas en el Extremo Norte de Chile. Chungara 8: 97-108.

Uribe, Mauricio

1998 Ms. La Iconografía de las Bandas-Fajas de la Litoescultura de Tiwanaku. Anexo 4 del Informe del primer año del Proyecto FONDECYT 1970073.

Vanstan, Ina

1969 Six Bags with Woven Pockets from Pre-Columbian Perú. Ñawpa Pacha 16: 17-31.

Vargas, Berta

1994 Ms. Informe Sobre Tumbas Intactas (334) Excavadas Durante el Proyecto "Rescate Arqueológico en el Cementerio de Chen Chen - Moquegua.”

Wassén, Henry

1972 A Medicine Man's Implements and Plants in a Tiahuanaco Tomb in Highland Bolivia. Etnologiska Studier XXXII. Göteborg: The Ethnographic Museum.

Zighelboim, A.

1991 Ms. An Iconographic Study of Stela Bennett. Unpublished Paper, University of Illinois at Urbana-Champaign.

Zlatar, Vjera

1984. Cementerio Prehispánico Pica-8. Antofagasta: Universidad de Antofagasta. 